I.N. Khlopenko, S.A. Rozhkov, N.J. Khlopenko

\title{
STABILITY AND ACCURACY OF THE ROBUST SYSTEM FOR STABILIZING THE ROTOR FLUX-LINKAGE OF AN ASYNCHRONOUS ELECTRIC DRIVE AT RANDOM VARIATIONS OF THE UNCERTAIN PARAMETERS WITHIN THE SPECIFIED BOUNDARIES
}

Purpose. The aim is to investigate the stability and the accuracy of a robust system for stabilizing the rotor flux-linkage of an asynchronous electric drive at random variations of the uncertain parameters of the object and the regulator within the specified boundaries. Methodology. To make the research, the mathematical model of the rotor flux-linkage channel of the vector control system of an asynchronous electric drive with parametric uncertainty was applied. The transfer function of the $H_{\infty}$-suboptimal regulator was calculated using the mixed sensitivity method. This transfer function was used to construct the regulator structural scheme in the form of a connection of proportional and integrating links and several adders. Analytical dependences of the coefficients of the regulator's transfer function on the parameters of links of such a connection are determined. These dependences served to researching the influence of uncertain parameters of the regulator links and the object on the stability of the robust system and the accuracy of flux-linkage stabilization. Results. Investigations of the robust system stability and the accuracy of flux-linkage stabilization in the Robust Control Toolbox are done. The curves of the fluxlinkage transient processes and the Bode diagram for the open system at random variations of the indeterminate parameters of the object and the regulator links within the specified boundaries are constructed. A choice of variable parameters was carried out by the Monte Carlo method. By the scatter of the obtained curves of the transient processes, the accuracy of flux-linkage stabilization was determined, and according to the Bode diagram, stability reserves in the amplitude and the phase of the robust system were determined. A high accuracy of flux-linkage stabilization (deviation less than $1 \%$ ) in fairly wide ranges of changing the uncertain parameters of the object and the regulator, while maintaining the stability of the system with permissible reserves in amplitude and phase, is established. Originality. For the first time, analytical dependences of the coefficients of the transfer function of the $H_{\infty}$-suboptimal regulator on the parameters of its structural scheme, which represented in the form of a connection of proportional and integrating links, are obtained. The method for calculating the stability of a robust flux-linkage control system and the accuracy of its stabilization at random variations of the uncertain parameters of the object and the regulator links within the specified boundaries is developed. Practical value. The use of the proposed method allows, during the design of the regulator, to ensure the selection of its elements from standard series. References 10, figures 3.

Key words: electric drive, vector control, flux-linkage channel, stabilizing robust system, stability, accuracy.

Цель. Целью работы является исследование устойчивости и точности робастной системы стабилизации потокосцепления ротора асинхронного электропривода при случайных вариациях неопределенных параметров объекта и регулятора в заданных границах. Методология. Для проведения исследований применялась математическая модель канала потокосцепления ротора системы векторного управления асинхронного электропривода $c$ параметрической неопределенностью. Рассчитывалась передаточная функция Н субоптимального регулятора по методу смешанной чувствительности. Эта передаточная функция использовалась для построения структурной схемы регулятора в виде соединения пропорциональных и интегрирующцих звеньев и нескольких сумматоров. Определялись аналитические зависимости коэффициентов передаточной функции регулятора от параметров звеньев такого соединения. Эти зависимости служили для исследования влияния неопределенных параметров звеньев регулятора и объекта на устойчивость робастной системы и точность стабилизации потокосцепления. Результаты. Проведены исследования устойчивости робастной системы и точности стабилизации потокосцепления в пакете Robust Control Toolbox. Построены кривые переходных процессов потокосцепления и диаграмма Боде для разомкнутой системы при случайных вариациях неопределенных параметров объекта и звеньев регулятора в заданных границах. Выбор варьируемых параметров осуществлялся по методу МонтеКарло. По разбросу полученных кривых переходных процессов определялась точность стабилизации потокосцепления, а по диаграмме Боде - запасы устойчивости по амплитуде и фазе робастной системы. Установлена высокая точность стабилизации потокосцепления (отклонение менее 1 \%) в достаточно широких диапазонах изменения неопределенных параметров объекта и регулятора при сохранении устойчивости системы с допустимыми запасами по амплитуде и фазе. Новизна. Впервые получены аналитические зависимости коэффициентов передаточной функции $\mathrm{H}_{\infty}$-субоптимального регулятора от параметров его структурной схемы, представленной в виде соединения пропорциональных и интегрирующих звеньев. Построена методика расчета устойчивости системы робастного управления потокосцепления и точности его стабилизации при случайных вариациях неопределенных параметров объекта и звеньев регулятора в заданных границах. Практическое значение. Использование предложенной методики позволяет в процессе конструирования регулятора обеспечить выбор его элементов из стандартных рядов. Библ. 10, рис. 3.

Ключевые слова: электропривод, векторное управление, канал потокосцепления, робастная система стабилизации, устойчивость, точность.

Introduction. In [1] the method of structural synthesis is constructed and the structure of the stabilizing robust $H_{\infty}$-suboptimal regulator is obtained in the form of a connection of proportional and integrating links for the flux-linkage channel of the vector control system of an 
asynchronous electric drive with parametric uncertainty of the control object. However, when designing such a regulator from analog devices (operational amplifiers and $\mathrm{RC}$-circuit) there are rounding errors of its gain factors and time constants due to the selection of elements (resistors, capacitors) of these devices from standard series. The consideration of such rounding errors in the calculation model of the regulator with parametric uncertainty of the object is of fundamental importance for ensuring the stability of the robust system and the necessary accuracy of flux-linkage stabilization.

Robust systems of stabilizing the parameters of asynchronous electric drives are engaged in a number of domestic and foreign scientists [2-9]. They solved many problems both in the development of mathematical methods of research, and in studying the stability, accuracy of regulation, and the speed of systems with a given uncertainty of the object. However, the problem of the influence of the parametric uncertainty of the robust regulator on the stability and accuracy of the flux-linkage stabilization system was not considered. In this connection, the problem of studying the stability of a robust system and the accuracy of stabilizing the rotor flux-linking with the parametric uncertainty of the object and the regulator within given boundaries seems to be actual.

The goal of the work is study of the stability and accuracy of a robust system for stabilizing the rotor fluxlinkage of an asynchronous electric drive at random variations of the indeterminate parameters of the object and the regulator within given boundaries.

Methods and results of research. The paper [1] contains a system of equations of state of an object consisting of a frequency converter and stator and rotor windings in the normal operator form:

$$
\begin{aligned}
& p x_{1}=-\frac{1}{T_{2}} x_{1}+\frac{L_{12} I_{\mathrm{n}}}{T_{2} \Psi_{\mathrm{n}}} x_{2} ; \\
& p x_{2}=-\frac{1}{T_{1 \mathrm{eq}}} x_{2}+\frac{E_{\mathrm{n}}}{R_{1 \mathrm{eq}} T_{1 \mathrm{eq}} I_{\mathrm{n}}} x_{3} ; \\
& p x_{3}=-\frac{1}{T_{\mathrm{fc}}} x_{3}+\frac{K_{\mathrm{fc}} U_{\mathrm{n}}}{T_{\mathrm{fc}} E_{\mathrm{n}}} u,
\end{aligned}
$$

where

$$
x_{1}=\frac{\Psi}{\Psi_{\mathrm{n}}} ; x_{2}=\frac{I}{I_{\mathrm{n}}} ; x_{3}=\frac{E}{E_{\mathrm{n}}} ; u=\frac{U}{U_{\mathrm{n}}} ;
$$

$p$ is the Laplace operator; $E$ is the frequency converter's EMF; $U$ is the control action; $I$ is the current in the rotor flux-linkage channel; $\Psi$ is the rotor flux-linkage vector's module; $T_{\mathrm{fc}}$ is the time constant of the frequency converter; $T_{1 \text { eq }}=L_{\text {leq }} / R_{\text {leq }}$ is the electromagnetic time constant of the stator winding, where $R_{1 \mathrm{eq}}=R_{1}+\left(k_{\mathrm{r}}\right)^{2} R_{2}$ and $L_{\text {leq }}=\sigma L_{1}$ are its equivalent resistance and the leakage inductance; $R_{1}, R_{2}$ are the active resistances of the stator and rotor windings; $T_{2}=L_{2} / R_{2}$ is the electromagnetic time constant of the rotor winding; $L_{1}, L_{2}$ are the inductances of the stator and rotor windings; $L_{12}$ is the mutual inductance of the stator and rotor windings; $\sigma=1-\left(L_{12}\right)^{2} /\left(L_{1} L_{2}\right)$ is the coefficient of magnetic field scattering; $k_{\mathrm{r}}=L_{12} / L_{2}$.

In this paper, this system of equations, together with the undefined parameters $K_{\mathrm{fc}}, R_{\text {leq }}, R_{2}, L_{1}, L_{2}$ and $L_{12}$ of the object, is used to construct a mathematical model for the stability and accuracy of a robust system for stabilizing the rotor flux-linkage of an asynchronous electric drive at random variations of uncertain parameters within given boundaries.

To construct such a model, the system of equations (1) is reduced to the canonical form [1]:

$$
\begin{gathered}
p x=A x+B_{1} w+B_{2} u \\
z=C_{1} x+D_{11} w+D_{12} u \\
y=C_{2} x+D_{21} w+D_{22} u,
\end{gathered}
$$

where

$$
A=\left[\begin{array}{ccc}
-\frac{R_{2 \mathrm{n}}}{L_{2 \mathrm{n}}} & \frac{R_{2 \mathrm{n}}}{L_{2 \mathrm{n}}} & 0 \\
0 & -\frac{R_{\text {leq }}}{L_{\text {leqn }}} & \frac{R_{\text {leq } \mathrm{n}}}{L_{\text {leq } \mathrm{n}}} \\
0 & 0 & -\frac{1}{T_{\mathrm{fc}}}
\end{array}\right]
$$$$
B_{1}=\left[\begin{array}{ccccccc}
0 & 0 & 0 & \frac{p_{R_{2}}}{L_{2 \mathrm{n}}} & \frac{p_{L_{12}}}{L_{2 \mathrm{n}}} & -p_{L_{2}} & -\frac{p_{R_{2}}}{L_{2 \mathrm{n}}} \\
0 & -p_{L_{\mathrm{leq}}} & -\frac{p_{R_{\text {leq }}}}{L_{\text {leq }}} & 0 & 0 & 0 & 0 \\
\frac{p_{K_{\mathrm{fc}}}}{T_{\mathrm{fc}}} & 0 & 0 & 0 & 0 & 0 & 0
\end{array}\right] \text {; }
$$$$
C_{1}=\left[\begin{array}{ccc}
0 & 0 & 0 \\
0 & -\frac{R_{1 \text { leq }}}{L_{\text {leqn }}} & \frac{R_{1 \text { eq } \mathrm{n}}}{L_{\text {leq } \mathrm{n}}} \\
0 & R_{1 \text { eq } \mathrm{n}} & 0 \\
0 & R_{2 \mathrm{n}} & 0 \\
0 & R_{2 \mathrm{n}} & 0 \\
-\frac{R_{2 \mathrm{n}}}{L_{2 \mathrm{n}}} & \frac{R_{2 \mathrm{n}}}{L_{2 \mathrm{n}}} & 0 \\
R_{2 \mathrm{n}} & 0 & 0
\end{array}\right] ; C_{2}=\left[\begin{array}{lll}
1 & 0 & 0
\end{array}\right]
$$

$$
D_{11}=\left[\begin{array}{ccccccc}
0 & 0 & 0 & 0 & 0 & 0 & 0 \\
0 & -p_{L_{\text {leq }}} & -\frac{p_{R_{\text {leq }}}}{L_{\text {leq n }}} & 0 & 0 & 0 & 0 \\
0 & 0 & 0 & 0 & 0 & 0 & 0 \\
0 & 0 & 0 & 0 & 0 & 0 & 0 \\
0 & 0 & 0 & p_{R_{2}} & 0 & 0 & 0 \\
0 & 0 & 0 & \frac{p_{R_{2}}}{L_{2 \mathrm{n}}} & \frac{p_{L_{12}}}{L_{2 \mathrm{n}}} & -p_{L_{2}} & -\frac{p_{R_{2}}}{L_{2 \mathrm{n}}} \\
0 & 0 & 0 & 0 & 0 & 0 & 0
\end{array}\right] ;
$$

$$
\begin{gathered}
B_{2}^{T}=\left[\begin{array}{ccc}
0 & 0 & \frac{1}{T_{\mathrm{fc}}}
\end{array}\right] ; \quad D_{12}^{T}=\left[\begin{array}{llllllll}
1 & 0 & 0 & 0 & 0 & 0 & 0
\end{array}\right] ; \\
D_{21}=\left[\begin{array}{lllllll}
0 & 0 & 0 & 0 & 0 & 0 & 0
\end{array}\right] ; D_{22}=[0] ;
\end{gathered}
$$


$x=\left(x_{1}, x_{2}, x_{3}\right)^{T}$ is the phase vector; $y$ is the onedimensional output vector which closes the feedback; $z=\left(z_{1}, z_{2}, \ldots, z_{7}\right)^{T}, w=\left(w_{1}, w_{2}, \ldots, w_{7}\right)^{T}$ are, respectively, the input and output uncertainty vectors interconnected by the matrix expression $w(p)=\Delta(p) \cdot z(p)$ in which the uncertainty matrix $\Delta(p)$ has a diagonal form.

The written canonical form of equations (2) together with the weight functions [10] for control the quality of the robust stabilization system, allows in the Robust Control Toolbox to calculate the transfer function of the $H_{\infty}$-suboptimal regulator for the nominal object. This transfer function can be represented in the form

$$
K(p)=k \frac{p^{2}+b_{1} p+b_{2}}{p^{3}+a_{1} p^{2}+a_{2} p+a_{3}},
$$

where $k, a_{1}, a_{2}, a_{3}, b_{1}, b_{2}$ are the regulator parameters.

We assume that the transfer function of the regulator (3) retains its form for random variations of the parameters $k, a_{1}, a_{2}, a_{3}, b_{1}, b_{2}$.

Then, expanding (3) into a continued fraction by the Euclidean algorithm, we obtain the block diagram of the regulator shown in Fig. 1. It contains the undefined parameters $k, k_{1}, k_{2}, k_{3}, T_{1}, T_{2}$, caused, as already noted earlier, by rounding errors that occur when designing the regulator.

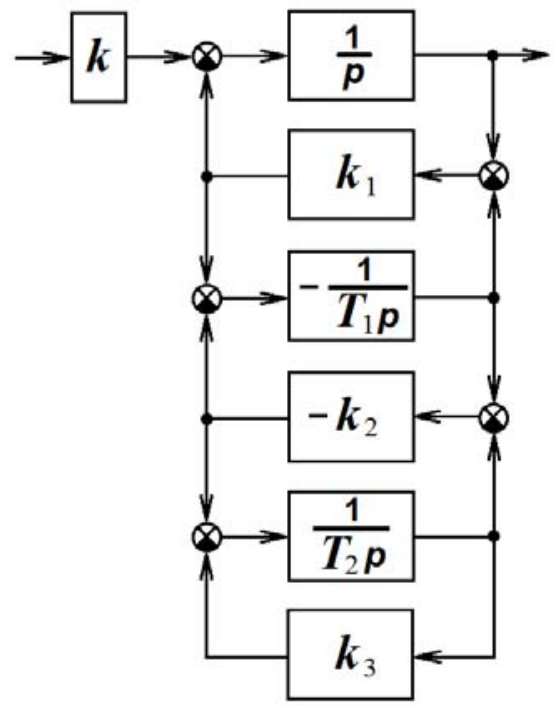

Fig. 1. Structural scheme of $H_{\infty}$-suboptimal stabilizing robust controller

We replace the structural scheme shown in Fig. 1 by equivalent circuit under the rules of transformation of structural schemes. Then we obtain the following expressions for the coefficients of the polynomials of the numerator and denominator of the transfer function of the robust regulator (3):

$$
\begin{gathered}
b_{1}=\frac{1}{T_{1}}\left(k_{2}-k_{1}\right)+\frac{1}{T_{2}}\left(k_{3}-k_{2}\right) ; a_{1}=k_{1}+b_{1} ; \\
b_{2}=\frac{1}{T_{1} T_{2}}\left[k_{3}\left(k_{2}-k_{1}\right)+k_{1} k_{2}\right] ;
\end{gathered}
$$

$$
a_{2}=b_{2}+k_{1}\left[\frac{k_{2}}{T_{1}}+\frac{1}{T_{2}}\left(k_{3}-k_{2}\right)\right] ; \quad a_{3}=\frac{k_{1} k_{2} k_{3}}{T_{1} T_{2}} \text {. }
$$

The system of equations (1) together with (3) and expressions (4) serves to investigate the stability and accuracy of the rotor flux-linkage stabilization system at random variations of the indeterminate parameters of the object and regulator within given boundaries.

The accuracy of flux-linkage stabilization is determined by the spread of the curves of its modulus of transient processes, and the stability reserves by amplitude and phase - according to the Bode diagram at various random variations of the undefined parameters of the regulator $k, k_{1}, k_{2}, k_{3}, T_{1}, T_{2}$ and the object $K_{\mathrm{fc}}, R_{1 \text { eq }}, R_{2}$, $L_{1}, L_{2}, L_{12}$ within specified boundaries. In this case, the Monte Carlo method is used for random choice of parameters [10]. Calculations are performed in MATLAB and terminated when, in the steady state mode of the system, transients do not exceed the boundaries of a onepercent «tube».

The procedure for calculating the stability and accuracy of the rotor flux-linkage stabilization system at random variations of undefined parameters within given boundaries is reduced to the following sequence of actions:

1. The transfer function (3) of the regulator for the nominal object is calculated.

2. The decomposition of the found transfer function into a continued fraction is performed.

3. The block diagram of the regulator is formed (see Fig. 1) corresponding to a continued fraction, and its nominal parameters $k_{\mathrm{n}}, k_{1 \mathrm{n}}, k_{2 \mathrm{n}}, k_{3 \mathrm{n}}, T_{1 \mathrm{n}}, T_{2 \mathrm{n}}$ are calculated.

4. The transfer function of the object (1) is programmatically determined.

5 . The system is formed by the command of fluxlinkage stabilization from the series-connected transfer functions of the regulator (3) and the object (1) covered by a single feedback.

6 . The curves of the flux-linkage transients and the Bode diagram for the open system are calculated with random variations of the parameters of the object $K_{\mathrm{fc}}$, $R_{1 \text { eq }}, R_{2}, L_{1}, L_{2}, L_{12}$ and regulator $k, k_{1}, k_{2}, k_{3}, T_{1}, T_{2}$ within the specified boundaries.

7. The accuracy of the flux-linkage stabilization is determined from the scales of the curves of the transients, and the stability reserves in the amplitude and phase are determined from the Bode diagram.

The numerical solution was carried out at the following values of the initial data: $T_{\mathrm{fc}}=0.001 \mathrm{~s}$; $R_{1 \mathrm{n}}=2.65 \Omega ; R_{2 \mathrm{n}}=2.0 \Omega ; L_{1 \mathrm{n}}=0.186 \mathrm{H} ; L_{2 \mathrm{n}}=0.189 \mathrm{H}$; $L_{12 \mathrm{n}}=0.179 \mathrm{H} ; \quad \sigma=0.0996$ corresponding the asynchronous electric drive with motor MDXMA100-32.

The nominal parameters of the regulator calculated from these data turned out to be equal to: $k_{\mathrm{n}}=5.016 \cdot 10^{5}$; $k_{1 \mathrm{n}}=1.436 \cdot 10^{4} ; k_{2 \mathrm{n}}=1.752 \cdot 10^{4} ; k_{3 \mathrm{n}}=3.473 \cdot 10^{3} ; T_{1 \mathrm{n}}=19.70 \mathrm{~s}$; $T_{2 \mathrm{n}}=1.256 \cdot 10^{3} \mathrm{~s}$. 
Undefined parameters of the object varied in the ranges $\pm 90 \%$, and the parameters of the regulator $k_{1}, k_{2}$ in the ranges $\pm 3 \%, k$-in the range $\pm 15 \%$, and $k_{3}, T_{1}, T_{2}$ in the ranges $\pm 20 \%$ of their nominal values.

Fig. 2 shows 20 curves of transients of the rotor flux-linkage corresponding to random variations of the undefined parameters of the object and the regulator selected within the prescribed boundaries by the Monte Carlo method. They are obtained in the packages of the MATLAB application for a single step change in the control action.

As can be seen, the curves of the transients shown in Fig. 2 do not exceed the limits of $1 \%$ of the tube.

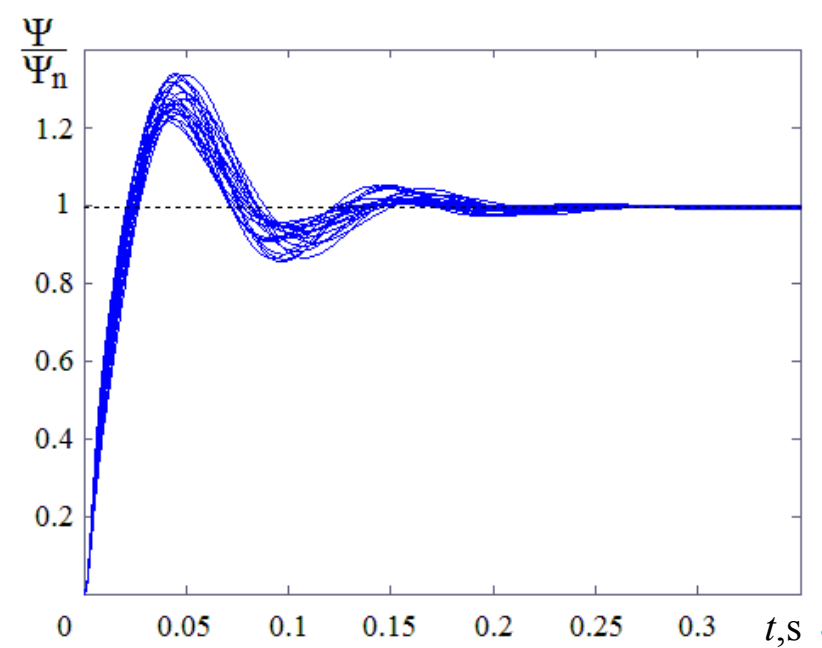

Fig. 2. Transients of the rotor flux-linkage

Fig. 3 shows the Bode diagram with 20 generated curves of amplitude $L(\omega)$ and 20 phase $\varphi(\omega)$ frequency characteristics with the same uncertain parameters as in the previous case.
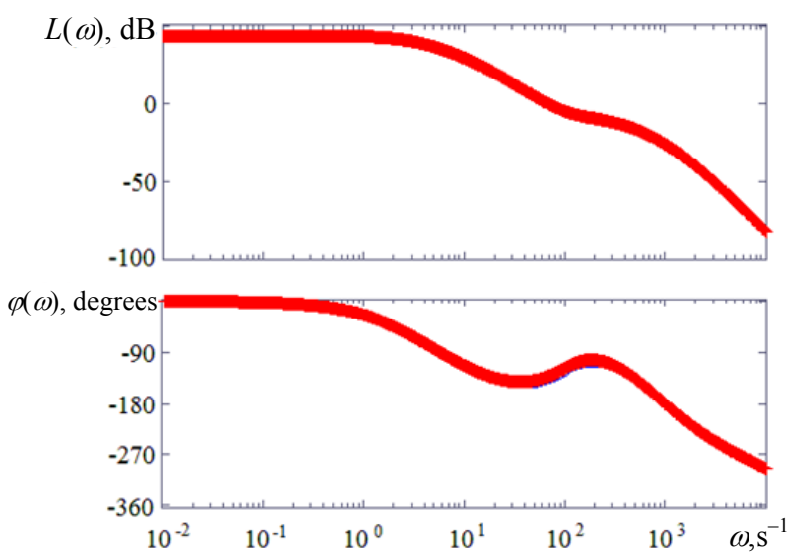

Fig. 3. The Bode diagram of the open system

From the amplitude $L(\omega)$ and phase $\varphi(\omega)$ characteristics presented in this diagram, it is seen that the system is stable, since the amplitude characteristic crosses the abscissa axis before the phase characteristic, finally decaying, goes over the value of the angle $-180^{\circ}$. In this case, the calculated value of the stability reserve in amplitude is $19.9 \mathrm{~dB}$, and in phase $-47.9^{\circ}$ for nominal values of the object and regulator parameters for variance of random curves not exceeding $4 \mathrm{~dB}$ for amplitude and $15^{\circ}$ for phase frequency characteristics.

Thus, the results of the calculations confirm the expediency of using the proposed method for constructing robust $H_{\infty}$-suboptimal regulators from elementary links.

\section{Conclusions.}

1. For the first time, analytical dependences of the coefficients of the transfer function of the $H_{\infty}$-suboptimal regulator from the parameters of its structural scheme represented as a combination of proportional and integrating links are obtained.

2. A method is developed for calculating the stability and accuracy of a robust system for stabilizing the rotor flux-linkage of an asynchronous electric drive at random variations of the indeterminate parameters of the object and the regulator within given boundaries.

3. The results of the calculations show a high accuracy of flux-linkage stabilization (deviation less than $1 \%$ ) and a low sensitivity of the robust stabilization system to random variations of uncertain parameters within given wide enough boundaries.

\section{REFERENCES}

1. Khlopenko N.J., Khlopenko I.N. Structural synthesis of a stabilizing robust controller of the rotor flux linkage. Electrical engineering \& electromechanics, 2017, no.1, pp. 21-25. (Rus). doi: 10.20998/2074-272X.2017.1.04.

2. Elistratov V.D., Ilina A.G. Robust control by servo drive with non-rigid load with $\mathrm{H}$-infinity norm limitation. Vestnik of Astrakhan State Technical University. Series: Marine Engineering and Technologies, 2016, no.4, pp. 89-94. (Rus). 3. Kuznetsov B.I., Nikitina T.B., Kolomiets V.V., Khomenko V.V. Investigation of the effect of nonlinearities and variations of the control object parameters on dynamic characteristics of the electromechanical servo systems. Bulletin of NTU «KhPI», 2015, no.12(1121), pp. 68-71. (Rus).

4. Nesenchuk A.A., Opeiko O.F., Odnolko D.S. Dynamics simulation and calculation of robust parameters for the electric drive control system on the basis of the root locus portraits. Artificial Intelligence, 2014, no.3, pp. 90-103. (Rus).

5. Nikitina T.B. Pareto optimal solution of multiobjective synthesis of robust controllers of multimass electromechanical systems based on multiswarm stochastic multiagent optimization. Electrical engineering \& electromechanics, 2017, no.2, pp. 34-38. doi: 10.20998/2074-272X.2017.2.05.

6. Peresada S.M., Kovbasa S.N., Bovkunovich V.S. Rough vector control torque and flux induction motor. Technical electrodynamics, 2010, no.1. pp. 60-66. (Ukr).

7. Potapenko E.M., Kazurova A.E., Savranskaya A.V. Review of works on dynamics of multimass uncertain electromechanical systems carried out in ZNTU electric drive department. Electrical Engineering and Power Engineering, 2011, no.1, pp. 7-10. (Rus). doi: 10.15588/1607-6761-2011-1-1.

8. Ostroverkhov M.J., Pyzhov V.M. Robust speed vector control system of gated inductor type electrical drive. 
Electromechanical and energy saving systems, 2015, I.N. Khlopenko ${ }^{1}$, Master of Science, iss.3/2015(31), pp. 32-38. (Ukr).

S.A. Rozhkov ${ }^{1}$, Doctor of Technical Sciences, Professor,

9. Rudnev E.S., Morozova D.I. $\mu$-synthesis of robust speed N.J. Khlopenko ${ }^{2}$, Doctor of Technical Sciences, Professor, controller of synchronous electric drives. Electrotechnic and ${ }^{1}$ Kherson State Marine Academy,

computer systems, 2015, no.20, pp. 42-50. (Rus). doi: 20, Ushakov Ave., Kherson, 73009, Ukraine,

10.15276/eltecs.20.96.2015.06. e-mail: rozhkov_ser@meta.ua

10. Richard Y., Chiang R., Michael G., Safonov M. MATLAB: $\quad{ }^{2}$ Admiral Makarov National University of Shipbuilding,

Robust Control Toolbox. User's Guide. Version 2, 1998. 230 p. 3, Central Ave., Nikolaev, 54021, Ukraine,

Available at: http://www.mathworks.com (Accessed 12 May e-mail:khlopenko.n@gmail.com

2016).

Received 23.04.2018

How to cite this article:

Khlopenko I.N., Rozhkov S.A., Khlopenko N.J. Stability and accuracy of the robust system for stabilizing the rotor flux-linkage of an asynchronous electric drive at random variations of the uncertain parameters within the specified boundaries. Electrical engineering \& electromechanics, 2018, no.4, pp. 35-39. doi: 10.20998/2074-272X.2018.4.06. 